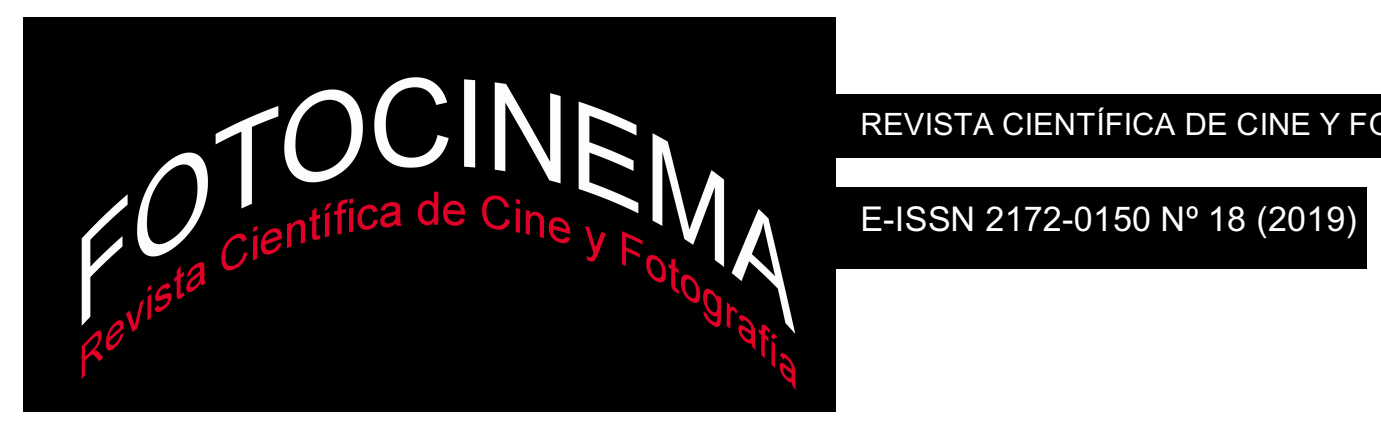

\title{
De guiones compartidos y otras ideas. Entrevista con Inés Bortagaray
}

\section{From shared screenplays and other ideas. Interview with Inés Bortagaray}

\section{Resumen}

\author{
David Vázquez Couto 1 \\ Universidad de Salamanca, España \\ davidcouto@usal.es
}

\begin{abstract}
Hace ya más de quince años que unos jóvenes cineastas dieron un giro inesperado al contexto cinematográfico uruguayo. Inés Bortagaray, figura clave del actual escenario cultural del país, formó parte de aquel fenómeno cuando, siendo estudiante de Ciencias de la Comunicación en la Universidad Católica del Uruguay, compartió clases, conversaciones sobre cine y buenos momentos de aprendizaje con un grupo de amigos que trastocarían el establishment del cine nacional afianzado durante años por la crítica conservadora. Inés Bortagaray nos habla de su etapa de formación personal y artística junto a aquel grupo de amigos, pero también del significado del guion, de su proceso creativo en la soledad y en la compañía del director o de otros guionistas, y en definitiva, de la autoría compartida en aras de algo mayor: el cine.
\end{abstract}

\begin{abstract}
:
More than fifteen years ago, young filmmakers made an unexpected turnaround in the Uruguayan film context. Inés Bortagaray, key figure in the current cultural scene of the country, was part of that phenomenon when being a student of Communication Sciences at the Catholic University of Uruguay, shared classes, conversations about cinema and good moments of learning with a group of friends who would disrupt the establishment of national cinema consolidated for years by the conservative film critic. Inés Bortagaray talks to us about her personal and artistic training with that group of friends, but also of the meaning of the screenplay, of her creative process in solitude and in the company of the director or other scriptwriters, and finally, shared authorship for the sake of something greater: cinema
\end{abstract}

Palabras clave: Inés Bortagaray; guion; cine; literatura; autor.

Keywords: Inés Bortagary; Screenplay; Cinema; Literature; Authorship.

\footnotetext{
${ }^{1}$ Esta entrevista ha sido realizada el 28 de septiembre de 2017 en Montevideo, en el marco del Proyecto de Investigación "Incidencia de la narrativa autorreferencial en la producción cinematográfica de Latinoamérica" (Universidad Católica del Uruguay) durante una estancia de investigación financiada por la Asociación Universitaria Iberoamericana de Postgrado (AUIP).

David Vázquez Couto es licenciado en Bellas Artes y en Comunicación Audiovisual por la Universidad de Salamanca, donde actualmente ejerce como Personal Investigador en Formación en el Departamento de Historia del Arte y Bellas Artes. También es miembro de la Asociación Española de Críticos de Arte (AECA), forma parte del equipo de trabajo del Proyecto de $\mathrm{I}+\mathrm{D}+\mathrm{i}$ "Intermedialidad e institución. Relaciones interartísticas: literatura, audiovisual, artes plásticas" (HAR2017-85392-P) y colabora con el Grupo de Investigación Reconocido "Investigación y transferencia en arte y cultura audiovisual (ITACA)", ambos de la Universidad de Salamanca.
} 
Inés Bortagaray (Salto, Uruguay, 1975) es autora de las novelas Ahora tendré que matarte (2001) y Prontos, listos, ya (2006), además de otros muchos relatos que han sido publicados en revistas y en volúmenes colectivos. En el terreno cinematográfico, además de haber trabajado en los castings de Whisky (Juan Pablo Rebella y Pablo Stoll, 2004) y La perrera (Manolo Nieto, 2006), ha sido co-guionista de los largometrajes Tokyo Boogie (Pablo Casacuberta y Yuki Goto, 2001), cuyo guion fue premiado con el FONA 2002 (Fondo para el Fomento y Desarrollo de la Producción Audiovisual en Uruguay); Una novia errante (Ana Katz, 2007); La vida útil (Federico Veiroj, 2010); Mujer conejo (Verónica Chen, 2013); Mi amiga del parque (Ana Katz, 2015), con la que ganó el Premio Especial del Jurado al Mejor Guion Internacional en el Festival de Sundance 2016; Al borde (Ana Katz, 2016); y Otra historia del mundo (Guillermo Casanova, 2017). También ha sido coguionista de la serie de televisión El fin del Mundo (Diego Arsuaga, 2004), y entre 2012 y 2013 escribió los guiones de Luna con dormilones (Pablo Uribe) y de El tiempo pasa, una obra para la Comedia Nacional realizada en el marco de Montevideo Capital Iberoamericana de la Cultura.

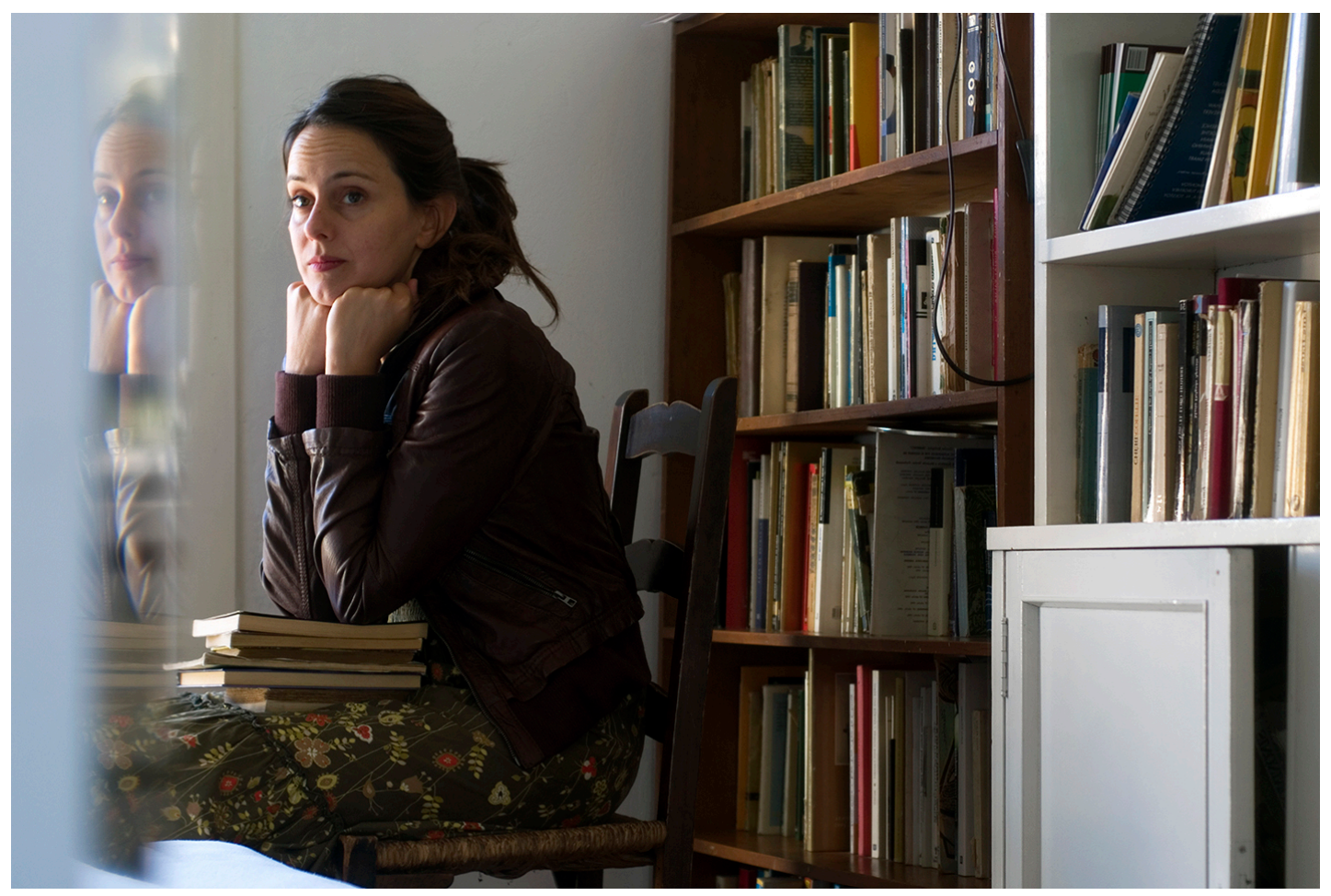

F1. Inés Bortagary, Montevideo, 2016. Fotografía de Magela Ferrero. 
DC: Un pequeño grupo de amigos revolucionarían el cine uruguayo a partir de la década del 2000 . La espontaneidad del fenómeno y su concreta localización y temporalidad, así como las trayectorias de los autores que se entrelazan constantemente a través de sus obras, inducen a los teóricos a pensar en una categoría o denominación válida que reúna sus particularidades de forma coherente. ¿Podría ser esta categoría la de "generación"?

IB: Sí, claramente. Todos, o casi todos los que estábamos en aquella especialidad de la licenciatura ("Narración creativa") han seguido trabajando en algo relacionado con lo audiovisual. Están, por ejemplo, Martín Borteiro, que se ha dedicado sobre todo al documental con un oficio más asociado a la televisión; Gillermo Amato, más vinculado al videoarte; Fernando Epstein, productor y editor; o Luis Castro, que hoy es gerente de programación en Canal 10. Creo que de una manera o de otra, todo sigue adelante.

DC: Hoy, tras muchas películas producidas, dirigidas, iluminadas, escritas, premiadas... seguís manteniendo un modelo de trabajo basado en la cooperación profesional. ¿La puesta en práctica de este sistema de trabajo se da en vosotros de forma natural?

IB: Siento que hay algo que sigue muy vivo entre nosotros, que es la amistad. Por ejemplo, con Pablo Stoll y con Federico Veiroj, con Arauco Hernández y con Gonzalo Delgado. Nos cruzábamos por los pasillos de la facultad y en el cine. Nuestra amistad es algo que nos une más allá de los proyectos que van armando esta especie de constelación donde todos participábamos de alguna manera. Nos buscamos porque hay una sensibilidad común, pero además, la experiencia técnica y la calidad profesional de cada uno de ellos hace que sea muy lógico que se les requiera para trabajar en cualquier proyecto.

DC: ¿Cuándo fue la primera vez que trabajaste de esta manera?

IB: Creo que fue con 25 Watts (Juan Pablo Rebella y Pablo Stoll, 2001). Aunque yo no trabajé en esta película y solo me pasé por el rodaje como amiga, pude comprobar cómo se utilizó un sistema cooperativo de trabajo que, creo, 
refleja muy bien la forma de asociación de donde partía el proyecto: de un grupo de amigos.

\section{DC: ¿Cuáles crees que fueron las afinidades personales $y$ cinematográficas comunes que contribuyeron a dar forma al grupo?}

IB: Éramos un grupo con mucha complicidad, muy próximos los unos a los otros, y comenzamos a pasar tanto tiempo fuera como dentro de la universidad. Nos íbamos al bar de la esquina a tomar grappamiel, íbamos al cine y luego discutíamos sobre la película que habíamos visto. Había algo muy germinal en todo esto que claramente me fue envolviendo desde el principio.

Dos cosas fueron importantes para mí y mi relación con el grupo. Una fue cuando a partir del segundo año, en el 94, me hice socia de la Cinemateca, y aquello me permitió adoptar una forma más sistemática y menos caprichosa de ver cine. En la Cinemateca veíamos las películas de Jim Jarmusch o de Hal Hartley, que a todos nos encantaban, pero allí también teníamos la posibilidad de ver de dónde venía ese tipo de cine, (de conocer cuáles eran sus referencias). Además, yo escribía desde niña, y los amigos, la Cinemateca, y más tarde el encuentro con Mario Levrero, me devolvieron a esa vocación.

Otra fue cuando a través del padre de Arauco Hernández, que era un pintor muy prestigioso acá llamado Anhelo Hernández Ríos (1922 - 2010), llegamos hasta Ferruccio "Fucho" Musitelli (1927 - 2013), el "cameraman", como se autodenominaba. El autor de La ciudad en la playa (1961) nos recibía a Juan Pablo Rebella, Pablo Stoll, Arauco Hernández, Natalia Lara y a mí en su casa los sábados por la mañana. Charlábamos sobre cine después de ver iQué verde era mi valle! (John Ford, 1941). Algunas veces debatíamos sobre la posibilidad de ir al Aconcagua a hacer un documental. Otras veces lo acompañé a la Biblioteca Nacional a buscar documentos. Aunque nunca llegamos a hacer nada con él, nos entusiasmaba y nos emocionaba con su pasión por el cine. 
DC: Los límites de las diferentes categorías profesionales del cine no siempre son claros. Evitar la intromisión en el terreno propio y ajeno puede ser tanto una ventaja organizativa como una desventaja creativa, pero cuando se escribe un guion con otros autores todo límite desparece. ¿Cómo afrontas la transformación de tu guion a manos de otros autores?

IB: Yo dudo mucho escribiendo. Tengo un pie en la literatura y otro en el cine. El cine me lleva a una experiencia mucho más compartida porque en general trabajo como coguionista, y como coguionista trabajo con el director o la directora. Ahí es cuando la complicidad encarna una manera de trabajar. Se tiene que instalar un diálogo que genere un universo arborescente y compartido de referencias culturales. Esa manera de pensar el trabajo como un tránsito, ya que una película, en general, es compleja y tiene ecos y resonancias en otras obras que no han de ser necesariamente cinematográficas. Todo eso, para mí, viene muy dado. Es una búsqueda que me surge muy naturalmente, aun cuando no trabajo con amigos o gente cercana. $\mathrm{Y}$ a veces esa confianza y complicidad resulta extraña cuando estás acostumbrado a un debate más íntimo, y de pronto, aparecen códigos y lenguajes nuevos.

DC: El guion lo elaboras de una manera más colectiva y la novela o el cuento de manera más íntima. Una vez dijiste que con Mario Levrero te habías reencontrado "con una forma más propia, un estilo más personal". ¿Cómo es posible conservar tu parte más personal dentro del guion compartido? Tengo la intuición de que obtienes una especie de satisfacción en la disolución de tu voz en la obra colectiva.

IB: Sí, totalmente. No sé si lo hubiera podido decir así porque no sé si lo tenía tan claro, pero al oírtelo decir me parece que sí. Claramente, lo que se pone por delante es la historia y no tengo celos de ese pedacito o esa línea del diálogo que es mía. 


\section{DC: ¿Y aun así tu voz es reconocible entre las demás?}

IB: No, porque en realidad hay una amalgama. Cuando se reconoce demasiado es que algo no está funcionando. Es muy estridente ver una identidad del autor donde debería estar la de los personajes (salvo cuando el personaje se mira en nuestro espejo o tiene nuestros tics).

\section{DC: ¿Hablas de una identidad propia de la película que es colectiva?}

IB: Yo creo que sí. Y eso se va ganando en el proceso de trabajo que tiene muchas capas, como por ejemplo la escritura, que tiene tantas reescrituras que en algún punto el texto empieza a tener vida propia.

\section{DC: ¿Cómo se controla esa vida propia? ¿Qué mecanismos entran en juego para modelar la forma de las ideas?}

IB: Debido a mi aprendizaje autodidacta no tuve una formación que me sirviera de apoyo. Todas las soluciones y todos los problemas me han venido en la práctica. Ahora es la primera vez en mi trabajo como guionista que siento que estoy estudiando más, que me estoy encontrando con la teoría y con la fórmula. Hasta ahora ha sido muy intuitivo para mí. Los logros, si los hay, pertenecen a esa intuición, y encontrando las claves de una manera tentativa, a ciegas. Esto tiene sus ventajas y sus desventajas. Cuando en el guion se profesionaliza mucho, he llegado a notar cierto automatismo, y así cuesta encontrar claves o soluciones. A veces aquello que funciona es lo que no funciona. Sé que es una respuesta muy confusa, pero creo que no tengo ninguna expectativa de que mi voz aparezca en el guion. Por otro lado, en $\mathrm{Mi}$ amiga del parque (2015), la última película que he escrito con Ana Katz, una amiga muy íntima, siento que hay una verdad, si se quiere decir así, o algo más "puro", si considerásemos puro como aquello que está por descubrir y conocer, que puede estar apareciendo porque hay un compromiso personal tan grande que es como si la materia de producción no estuviera filtrada por ninguna especulación asociada a la fórmula. 
DC: Parte de esa fórmula puede venir muy determinada por quien al final transforma el guion en imágenes, es decir, el director. ¿Sueles trabajar en los guiones de manera que queden cerrados a una realización posterior o trabajas simultáneamente a la dirección para resolver los posibles problemas que van surgiendo?

IB: Con Ana Katz, por ejemplo, trabajo con los guiones hasta el último momento, y así termino participando en esa última versión de rodaje. Quizás la explicación de esto tiene que ver con que estas películas, que si caen bajo un paraguas, es el del "cine de autor", o no sé muy bien cómo definirlo. Yo escribí mi primer guion en el año 2000 con Pablo Casacuberta, un escritor y artista visual de Montevideo, y tras más de quince años, siento que ahora estoy encontrando un camino más claro de formación. Me ha hecho falta, porque con la intuición uno llega hasta cierto punto, pero la práctica y el oficio te van dando un fogueo muy necesario, especialmente cuando como co-guionista trabajo con alguien con quien me complemente bien. Es lo que ocurre ahora mismo, que estoy escribiendo para unos directores de cine de Brasil. Veo cómo mis compañeros tienen un gran sentido de la estructura, y yo puedo zambullirme en los personajes.

Este es el camino de la profesionalización. Por ejemplo, el guion que estoy escribiendo ahora es solo una primera versión porque mi contrato así lo estipula. No sé si después lo voy a seguir desarrollando, pero en estos otros casos de los que hemos estado hablando, se siguieron hasta el final. El guion es una pieza dinámica y muy viva, sometida a las inflexiones del plan de rodaje, de las posibilidades que surgen, de algo que se cae... y eso me encanta. En este sentido, yo cultivo feliz el desapego. 